SECTION F

\title{
FOUNDATIONS FOR SHEAR WALL STRUCTURES
}

\author{
J.R. Binney* and T. Paulay**
}

\begin{abstract}
:
After defining design criteria in general for foundations of earthquake resisting reinforced concrete structures, principles are set out which govern the choice of suitable foundation systems for various types of shear wall structures. The choice of foundation systems depends on whether the seismic response of the superstructure during the largest expected earthquake is to be elastic or inelastic. For inelastically responding superstructures, preferably the foundation system should be designed to remain elastic. For elastically responding superstructures, suitable foundation systems may be energy dissipating, elastic or of the rocking type. Design criteria for each of these three foundation types are suggested.
\end{abstract}

\section{INTRODUCTION :}

The criterion for the design of foundations of earthquake resisting structures is that the foundation system should be capable of supporting the design gravity loads while maintaining the chosen seismic energy dissipating mechanisms of the structure. The foundation system in this context includes the foundation structure, consisting of reinforced concrete construction, piles, caissons and the supporting soil. The common terms used are in accordance with the definitions of Reference 1 .

It is evident that for this criterion a suitable foundation system for a given superstructure can be conceived only if the mechanisms by which earthquake actions are disposed of are clearly defined.

In most structures inelastic deformations during large earthquakes are expected. Consequently for these structures provisions are to be made for energy dissipation, usually by flexural yielding. It is vital that energy dissipation be assigned by the designer to areas within the superstructure or within the foundation structure in such a manner that the expected ductility demands will remain within recognized capabilities of the selected components. It is particularly important to ensure that any damage that might result in the foundation structure does not lead to a reduction of strength that might affect gravity load carrying capacity.

This paper attempts to set out the general principles that govern the choice of foundation systems for shear wall structures and of the appropriate design method. In particular the presentation relates suitable foundations to superstructures, which have been chosen to perform in a definite manner during the

* Structural Engineer, Beca, Carter, Hollings and Ferner, Consulting Engineers, Wellington.

** Professor of Civil Engineering, University of Canterbury, Christchurch largest earthquake that can be expected at the site. No attempt is made to provide detailed recommendations for the proportioning and detailing of various components of the foundation structure, as the principles involved are either well established or they have been recently reviewed elsewhere $(1,2)$. However, clear distinction is made in the applicability of detailing requirements for the two following possibilities of foundation response to earthquake actions.

Where there is no possibility during seismic response for inelastic deformations to occur in the foundation structure, normal detailing of reinforcement, as for structures subjected to gravity and wind loads only, is considered to be adequate. On the other hand, where during earthquake loading yielding is intended to occur also in components of the foundation structure, the affected members must be detailed for the expected ductile response in accordance with the relevant requirements of the concrete design code(3).

The analysis of the foundation structure is often very sensitive because the maonitude of actions, such as moments and shear forces, may be strongly affected by the distribution of stresses induced in the supporting soil. Therefore account should be taken of the uncertainty of soil strength and stiffness, particularly under dynamic repeated loading, by considering a range of possible values for soil stiffness.

\section{SELECTION OF THE TYPE OF FOUNDATION RESPONSE:}

To satisfy the stated criterion for the design of foundations, suitable foundation types must be chosen to enable the intended performance of the superstructure during the largest expected earthquake to be realized. Correspondingly the following groups of shear wall superstructures, examined in detail elsewhere $(4,5,5)$ must be considered.

For the sake of this review clear distinction is made between elastic and inelastic responses for both the superstructure and the foundation system. 
This emphasis is intended to illuminate the deterministic nature of the recommended seismic design philosophy, which should be employed whatever system is chosen. There will be cases where the combined superstructure-foundation systems will be such that it does not exactly fit into the categories presented in the following, and yet such a system could prove to be equally satisfactory. The principle outlined should enable designers to develop with ease satisfactory approaches also to intermediate foundation types.

\section{Ductile shear Wall structures}

In shear wall structures in which seismic energy dissipation is allocated to flexurally yielding regions, capacity design procedures should be used generally $(3,5,7)$ to ensure that ductility is derived from these plastic regions only and that other regions possess sufficient reserve strength to exclude the possibility in any event of brittle failure. Such shear wall structures are designed to sustain lateral static forces corresponding with structural type factors $S$ in the range of $0.8<S<1.6$. For such shear wall superstructures the foundations must be capable of transmitting the largest feasible actions to the supporting soil, otherwise the intended response of the superstructure cannot eventuate.

\section{Elastic Shear Wall Structures}

In certain cases, either by choice or because of circumstances, the response of the shear wall superstructure to the largest expected seismic excitation will be elastic. Foundation systems which are expected to sustain elastic superstructures may then be considered in three groups :

\subsection{Ductile foundation structures}

When the potential strength of a shear wall with respect to the specified lateral seismic loading is excessive, the designer might choose the foundation structure to limit the lateral load that can be resisted. In such cases the foundation structure rather than the superstructure, may be chosen to be the principal source of energy dissipation during the inelastic response of the entire system. Therefore all requirements relevant to ductile performance are applicable to the design of the components of such a foundation structure, which might yield.

\subsection{Elastic foundation systems}

When the "Elastic Response Procedure"

is the appropriate design method, using a structural type factor $\mathrm{S}=4$ or more, the entire structure is expected to respond within elastic limits. Usually only in low and long buildings will it be possible to satisfy overall stability (overturning) criteria for this high level of lateral static loading.

\subsection{Rocking structural systems}

A common feature in the design of earthquake resisting shear walls is a difficulty with which the flexural capacity of such, often moderately reinforced, walls can be absorbed by the foundation system without it becoming unstable, i.e. without overturning. For such situations the designer may choose rocking of the superstructure, together with its foundations, to be the limiting mechanism of earthquake resistance. This procedure may be acceptable at a load level corresponding with $\mathrm{S} \geqslant 2$, unless special studies are carried out as discussed in Section on 'Rocking Shear Wall Systems' Usually the shear wall and its foundation members should be designed to remain elastic during the rocking motion.

ELASTIC FOUNDATION SYSTEMS:

The design of the foundation system for elastically responding structures of section 2.2 does not require elaboration.

The simple principles relevant to ductile superstructures (section 1) may be stated as follows:

(a) The loading transmitted to the foundation structure should be derived from the appropriate combination of the earthquake and gravity induced actions at the base of shear walls, at the development of the overstrength of the relevant flexurally yielding sections in accordance with the principles of capacity design(5). In order to determine the corresponding design actions on various components of the foundation structure, the appropriate "soil or pile reactions" must be determined. In this it may be necessary to make limiting assumptions, as pointed out in the introductory section, to cover uncertainties in soil strength and stiffness.

When foundations are being provided for a ductile cantilever shear wall, designed in accordance with the recommendations of reference 5 , the loading transmitted from the inelastic super-structure to the foundation structure should be as follows:

(i) The bending moment should be that corresponding with the flexural overstrength of the base section of the wall, developed concurrently with the appropriately factored gravity load. This is $\phi_{0} M_{\text {code }}$ where $\phi_{0}$ is the flexural overstrength factor (5) and $M$ is the base moment derived from the code (7) specified lateral loading.

(ii) The earthquake induced shear force, assumed to be transmitted at the base of the cantilever should be taken as the critical shear force used in the design of the plastic hinge zone of the wall i.e. $V_{\text {wall }}=\phi_{0} \omega_{\mathrm{V}} \mathrm{V}_{\text {code, }}$ 
where $\omega_{\mathrm{f}}$ is the dynamic shear magnifications factors recommended in Reference 5 and $V_{\text {code }}$ is the shear force obtained from the code (7) loading.

(iii) In the presence of the above earthquake induced forces the appropriately factored gravity load should be taken as either dead plus live load, or 0.9 times the dead load only.

(b) All components of the foundation structure should have ideal strengths (5) equal to, or in excess of, the moments and forces that are derived from the seismic overstrength of the shear wall superstructure. Strength reduction factors $(\phi)$ need not be used in providing this ideal strength. This procedure is expected to ensure that yielding of any significance will not occur during any earthquake that does not disrupt the supporting soil.

(c) Bearing areas of footings, piles or caissons should be such that negligable inelastic deformations, if any, are developed in the supporting soil under actions corresponding to overstrength of the superstructure.

(d) Because yielding, and hence energy dissipation, is not expected to occur in components of a foundation structure so designed, the special requirements for seismic detailing of the reinforcement need not be satisfied. This means that reliance may be placed on the contribution of the concrete in accordance with the provisions of the Concrete code (3), to resist shear forces, and that transverse reinforcement for the purpose of confinement of the concrete or the compression bars need be provided only as in gravity loaded reinforced concrete structures.

(e) The principles outlined above apply equally to shear wall superstructures designed for limited ductility (6) if capacity design procedures are used.

\section{DUCTILE FOUNDATION SYSTEMS:}

For the type of foundation response described in section 2.1, the major source of energy dissipation is expected to be the foundation structure. Because of the difficulty in detecting and repairing damage in foundation structures, the consequences of damage during moderate earthquakes should be carefully weighed when considering such a structural system. When proceeding with the design, the following aspects should be taken into account:

(a) If energy dissipation is to take place in components of the foundation structure, then the designer must clearly define the areas of yieldino. Moreover, when members have proportions markedly different from beams the rotational ductilities likely to be imposed on potential plastic hinges may need to be checkea. The loading code(7) envisages inelastic deformations corresponding approximately with a displacement ductility factor of $4 / \mathrm{S}$, hence energy dissipating mechanisms of the ductile foundation structure must be capable of sustaining the corresponding elastic rotations.

(b) The loading at which plastic hinges of the ductile foundation structure could develop should be the same as for ductile shear wall superstructures. Consequently the structural type factors described in other sections $(4,5,6)$ may be considered to be relevant.

When the foundation element is squat, its length to depth ratio should be taken into account in determining the value of the structural type factor as for cantilever shear walls $(4,5)$. In this context the length of a foundation beam or wall should be taken as the distance from the point of zero moment to the section of maximum moment, where the plastic hinge is expected to develop.

(c) With respect to shear forces that might be induced in various components of the foundation structure, capacity design procedures, evaluating the flexural overstrength of potential plastic hinges, should be utilized. In deep foundation members, where shear is critical, diagonal principal reinforcement, similar to the system used in coupling beams of coupled shear walls, may be appropriate. All inelastic members of the foundation structure should be reinforced in accordance with the appropriate seismic requirements(3) for detailing.

(d) Special consideration should be given to the effects of inelastic, reversed and cyclic seismic actions on foundation beams, footing pads, piles, caissons and pile caps, because of the absence of experimental evidence related to the performance of these components under seismic type loading. Because inelastic foundations have not been the subject of known detailed study, existing code recommendations (3) do not necessarily cover all contingencies for such situations. Consequently caution and conservative detailing procedures should be adopted.

(e) At sections of the shear wall superstructure, where load is being transmitted to the ductile foundation structure, the ideal strength of the wall should be at least equal to the load required to develop the flexural overstrength of the foundation structure. Shear wall superstructures so designed should not need to meet the special seismic detailing requirements (3). 


\section{ROCKING SHEAR WALL SYSTEMS:}

Where special studies are made, shear walls may be assumed to limit the seismic load they need to resist, by rocking with their foundations. The dimensions and the locations of shear walls within a building may be such, that, even with the minimum flexural reinforcement content stipulated by the code(3), they would develop overturning moment capacities that would be difficult or impossible to resist at foundation level.

It has been suggested that foundations need not be designed for forces larger than those corresponding with $S=2$. It is not uncommon that shear wall structures would possess corresponding strengths, so that yielding in the superstructure would not occur when the lateral load corresponding with $S=2$ is reached. Rocking of the entire system is implied to occur at this stage. In this content rocking refers to soil-structure interaction. Rocking at other levels or the rocking of one part of the structure on another part is not implied here.

It is now recognized that with proper study, rocking should be acceptable at load levels less than that which corresponds with $S=2.0$. For rocking mechanisms the shear wall superstructure and its foundation structure should be considered as an entity. Because of the complete absence of experience with rocking buildings in earthquakes, the design should be based on special studies, including appropriate dynamic analyses (8), to verify the suitability of the rocking system. In considering actions on the foundations:

(a) The design vertical load on the rocking foundation structure of a shear wall should be determined from the factored gravity loads, together with overstrength contributions from slabs, beams or other elements, adjacent to shear walls, which may be yielding during rocking of the shear wall. The three dimensional nature of the behaviour of the entire structure must also be considered. Transverse beams, which may extend between the rocking wall and adjacent non-rocking frames must be detailed for ductility to preserve their integrity for carrying the intended gravity loads. Such members should be subject to capacity design procedures.

(b) The design lateral load, acting simultaneously with the vertical loads derived from considerations of the above section, should be determined from the load which is required to cause rocking and from the effect of linkages with other walls or frames through floor diaphragms. The total lateral load on the entire structure is derived from the summation of the lateral load on all rocking walls and nonrocking frames which are effectively interconnected by rigid floor diaphragms. (c) The lower limit for the lateral load, when rocking may be permitted to commence may be derived from the following considerations:

The structural type factor of $S=1.0$ is applicable to structures consisting of two or more ductile shear walls with or without ductile frames. It can be expected that in such structures no damage of significance, including damage to non-structural components, will occur when the lateral load reaches an intensity corresponding with $S=1.0$. For any additional load, which will be required to mobilize the ideal strength of structural components, inelastic deformations must be expected. Hence for such structures, which require special study, rocking of a shear wall should also be acceptable at or above this level of loading.

(d) A thorough analysis should be carried out to determine the ductility demands on components of the whole structure other than the rocking shear wall, to ensure that these do not exceed the ductility demands implied by the $S$ factor appropriate to those components. This implies a full assessment of the performance of structural and non-structural components of the building as a consequence of vertical and horizontal displacements associated with the rocking motion of shear walls.

(e) Rocking shear walls may impose large forces on the supporting soil. Therefore bearing areas within the foundation structure should be so proportioned as to protect the soil against excessive plastic deformations that would be difficult to predict, and which might result in premature misalignment of the otherwise undamaged shear wall or the entire building. This consideration may lead to the consideration of independent footings of adequate size that distribute the loading to the soil at points or lines of rocking to ensure that plastic deformations do not occur in the soil. Alternatively oversize footings should be provided to limit soil pressure to a safe value during rocking of the superstructure. Consideraton to soil response for various load conditions are given elsewhere(2).

(f) Where all actions on potentially rocking walls and their foundations are derived from capacity design procedures; including the effects of ductile non-rocking adjacent frames and other components, the rocking system may be considered to be sufficiently protected against overload, and hence against failure, if it possesses corresponding ideal strength(5). Therefore such rocking wall systems should be exempted from the requirements(3) for special seismic detailing of the reinforcement. 


\section{THE EFFECTS OF FOUNDATION DEFORMATIONS:}

The elastic and inelastic response of shear wall structures is very sensitive to deformations which originate in the foundation systems. Usually it is soil deformations, rather than component distortions within the foundation structure, which significantly affect the stiffness of shear walls. Unfortunately there are no reliable techniques available with which such deformations can be predicted with a degree of accuracy that is comparable with that accepted in the analyses of reinforced concrete superstructures(5). Within the limits of elastic response for both structure and soil, the Winkler foundation model, consisting of a set of vertical springs that simulate the modulus of subgrade reaction, may give some indication of base rotation due to lateral load. Provided that the ratio $\mathrm{M}_{f} / \mathrm{I}_{\mathrm{f}}$ for each cantilever wall in the building is approximately the same, the relative stiffnesses and hence the distribution of lateral design loads will not be affected significantly by base rotations. In the above ratio, $M_{f}$ is the overturning moment imposed by the lateral load on the footing of a cantilever shear wall, for which the second moment of the bearing area about its centroidal axis is $I_{f}$.

Where the absolute values of the deformations are required, for example for the assessment of the performance of nonstructural components and other parts of the building 99 , considerable

difficulties arise in the estimation of deflections. Suggestions for estimating soil deformations, also in the nonlinear range of respqnse, have been made by Taylor and Williams 2 .

When the elastic deformations of the soil are estimated their contribution may be included in the total deflection of the structure for the purpose of estimating the fundamental period of vibration. Because of the uncertainties involved in such an estimate, it is recommended that the ensuing reduction in the design base shear should not exceed $20 \%$ of the base shear determined from period computations that do not consider foundation deformations. It should be noted that inelastic deformations, required to develop the required displacement ductility, will then originate entirely in the plastic hinges of the superstructure, such as at the base of a ductile shear wall, or in the inelastic foundation structure, and not in the ground. such cases, for a given displacement ductility demand, much larger curvature ductility will be required in plastic hinges. This is because the yield displacement results from structural and soil deformations, but the inelastic displacements will originate from plastic distortions of the structure only.

\section{EXAMPLE FOUNDATION STRUCTURES:}

To illustrate the relevance of the design philosophy outlined in previous sections, a few examples, necessarily oversimplified, are introduced and discussed.

\section{Example 1 -}

A simple cantilever shear wall, subjected to earthquake and gravity loading, is shown in Figure $1(\mathrm{a})$. Its foundation consists of a spread footing. The base shear is assumed to be transmitted by friction at the underside and by bearing at the end of the footing pad. It is evident that it will be difficult to develop substantial tension within the wall at its edge. Tensile forces introduced by the principal flexural reinforcement at the tension edge of the wall could not be transferred beyond the anchorages of the bars within the footing. For this reason a ductile plastic hinge could not develop at the base of this wall. The structure possesses limited base fixity and it may be necessary to consider its contribution in the rocking mode, unless exceptionally large gravity forces are to be transmitted.

When piles or caissons with significant tensile capacity are provided, as shown in Figure l(b), the flexural capacity of the cantilever wall at its base could be developed. The potential plastic hinge zone at the wall base, where special detailing requirements (3) need to be satisfied, is shown by the shaded area. In accordance with the principles of the section on Elastic Foundation systems the footing or pile cap and the piles would need to be provided with ideal strengths at least equal to the flexural overstrength of the cantilever wall.

Example 2 -

Two cantilever shear walls are supported on a common foundation structure, consisting of piles and a deep foundation beam as shown in Figure 2. Arrows indicate qualitatively the load due to gravity and earthquake and the corresponding reactions at the foundation-soil interface. With a strong and stiff foundation beam or wall, the major part of the moments introduced by the cantilevers through the potential plastic hinge regions, again shown shaded in figure 2, may be resisted by the portion of the foundation structure between the inner faces of the two walls. The design for shear in this region will require special attention. When actions on the foundation are derived from capacity design consideration, in accordance with the section on Elastic Foundation Systems yielding in the foundation structure can be prevented and consequently the contribution of the concrete to shear strength can be relied upon. With this type of foundation structure the load on the piles can be considerably reduced and the formation of the intended plastic hinges in the walls can be assured.

Example 3 -

It is often difficult, if not impossible, to provide base fixity for shear walls located adjacent to the boundary of the building. 


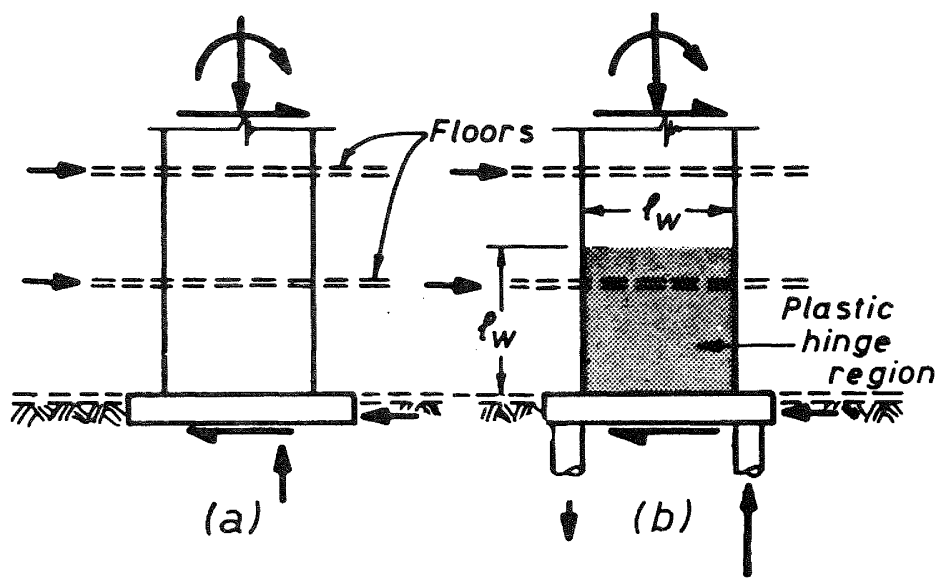

Fig. 1 - Foundations for isolated cantilever walls.

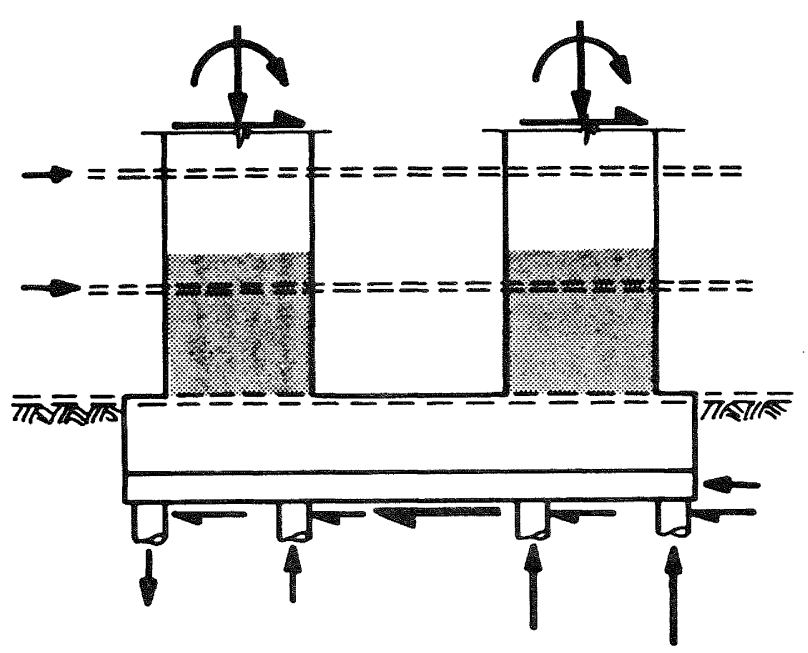

Fig. 2 - Foundation for two cantilever walls.

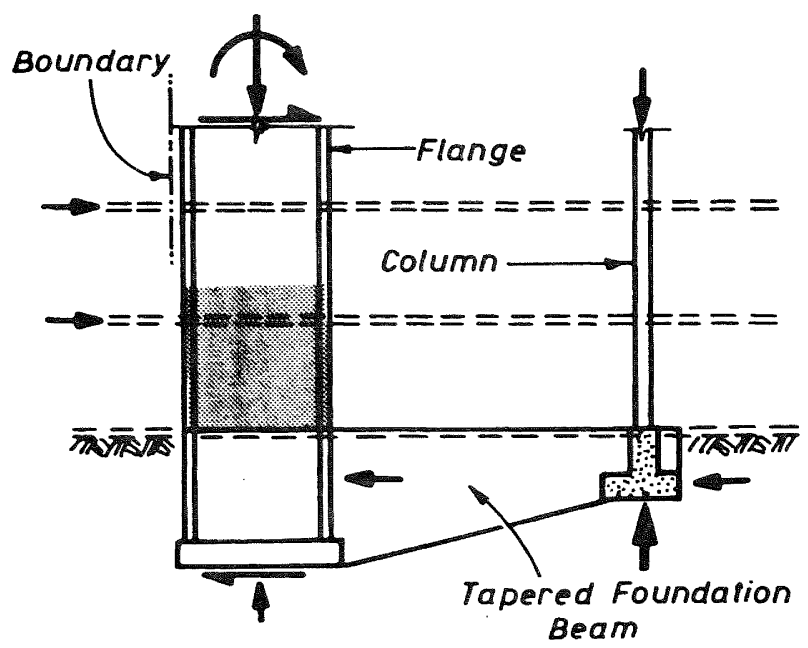

Fig. 3 - Foundation for wall adjacent to a boundary 
Shear cores, accommodating lift and stair wells and consisting of two or more flanged walls, are often assigned a major part of the lateral load resistance. This requires the transmission of large overturning moments to the foundations.

Figure 3 shows one solution whereby a deep foundation beam interconnects the shear core with one or more adjacent columns. Thereby the internal lever arm, required to resist the overturning moment introduced at the wall base, is increased, and hence the forces to be transferred to the supporting soil are reduced. Moreover, the gravity load on the columns can be made use of in stabilizing the shear core against overturning when earthquake forces, opposite to those shown in figure 3 , act on the building.

In designing the foundation structure the flexural overstrength of the wall base should again be considered to determine the design forces. Particular attention needs to be paid to the junction of the wall and the foundation beam, which should be designed as a large knee joint subjected to reversed cyclic loading(10). Special shear reinforcement in two directions will be required in this area.

\section{Example 4 -}

The capacity of coupled shear walls to resist overturning moment can be considerably more than the sum of the moment of resistance of the walls which are being coupled. Therefore massive foundations will be required to enable ductile coupled shear walls to develop their full potential as major energy dissipating structural systems. Figure 4 shows the foundation wall receiving the load from a coupled shear wall superstructure and two columns at the boundary of the building. The potential plastic hinge regions within the ductile superstructure are again indicated by the shaded areas. The foundation wall is shallow relative to the coupled walls and therefore it may require considerable amounts of flexural reinforcement to resist at ideal strength the overstrength overturning moment input from the coupled shear walls. of particular importance is the area under the central opening at ground floor level, where very large shear forces may need to be transferred.

\section{Example 5 -}

Cantilever or coupled shear walls assigned to resist the major part of the lateral earthquake load and placed at the ends of long buildings usually carry relatively small gravity load. For this reason it is difficult to provide foundations for them that are large enough to ensure that these walls will not overturn or rock prior to the development of their flexural overstrength. In such situations the foundations of end shear walls may need to be connected to the remainder of the structure, situated between the ends, in order to "collect" additional gravity loads. Figure 5 shows such a situation.
The end-walls are connected to a box-type foundation structure, consisting of peripheral and perhaps internal foundation walls, supporting a raft and a ground floor slab. Fixity of the ductile cantilever walls is provided by the peripheral long foundation walls which usually also support a row of columns. Because the reactive pressure due to overturning moments, introduced by the end walls, may be induced primarily under the longitudinal foundation walls, these walls are usually subjected to very large bending moments. This requires massive flexural reinforcement both in the top and the bottom of the foundation walls.

The demand for flexural reinforcement in the exterior foundation walls may be considerably reduced if the cantilever shear walls are placed away from the ends. In figure 5 a more advantageous position for these walls is marked $w$.

\section{Example 6 -}

When a basement is provided with deep peripheral foundation walls, it may be more convenient to transfer the base moment due to earthquake loading on interior shear walls or shear cores to long exterior foundation walls. Such an interior flanged shear wall is shown in figure 6. The spread footing under the wass is provided primarily to resist vertical loading on the wall. The moment at the development of the flexural overstrength of the ductile cantilever wall $\mathrm{M}^{\mathrm{O}}$ is to be transferred by means of a horizontal force couple to the ground floor and basement slabs respecively. Consequently these slabs are to be designed as diaphragms to transfer the forces to peripheral or other long foundation walls.

The degree of fixity of the wall, where it is in contact with the soil, may be difficult to evaluate and some estimate between extreme limits, indicated in the bending moment diagram of figure 6 , may have to be made. In any case some base fixity should be assumed to ensure that the shear in the wall, between basement and ground floor level, is not underestimated. The large shear force in this relatively short region may warrant the use of some diagonal shear reinforcement.

The extent of the plastic hinge region (shown shaded) below ground floor level is not clearly defined. Detailing of the reinforcement for ductility of this region should not be overlooked. Such detailing should be used over the length $l$ below ground level or down to the basement, whichever is the smaller distance.

\section{Example 7 -}

Whereas it would be difficult to develop in individual footings the full moment capacity of cantilever walls, this could be achieved when a massive foundation beam, interconnecting two or more cantilever walls, as shown in figures 2 and 7 , is used. In accordance with the section on 'Ductile Foundation Systems' the designed may choose 


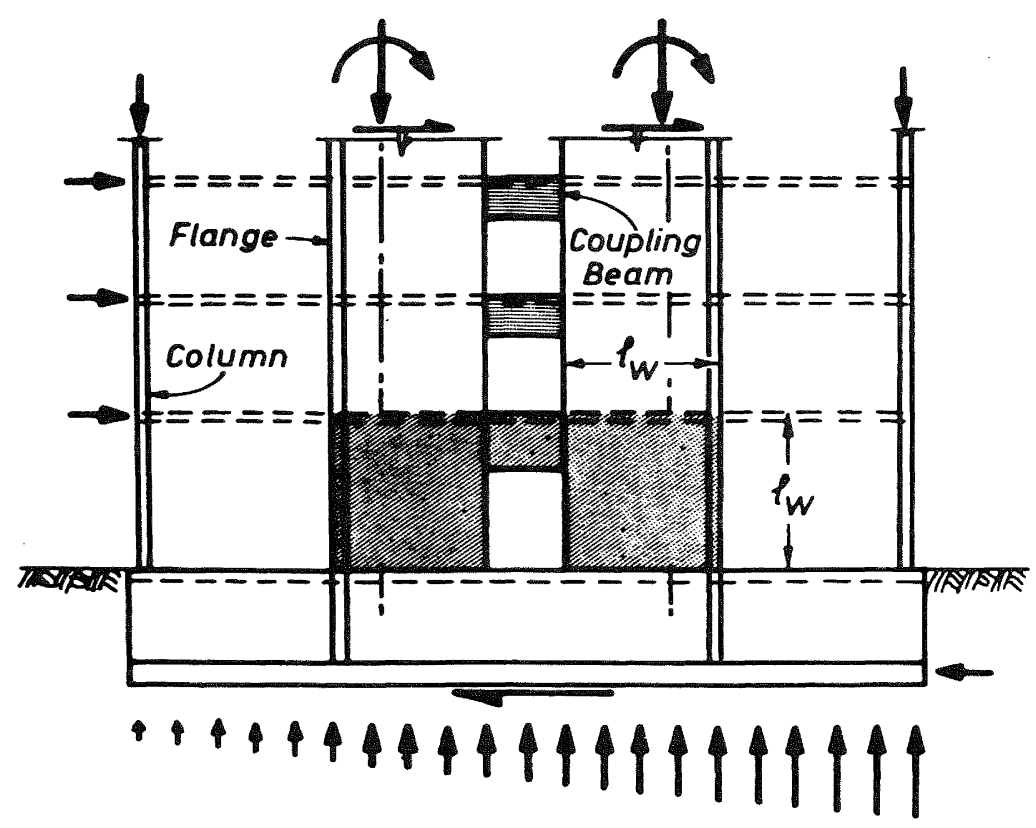

Fig. 4 - Foundation for a coupled shear wall structure.

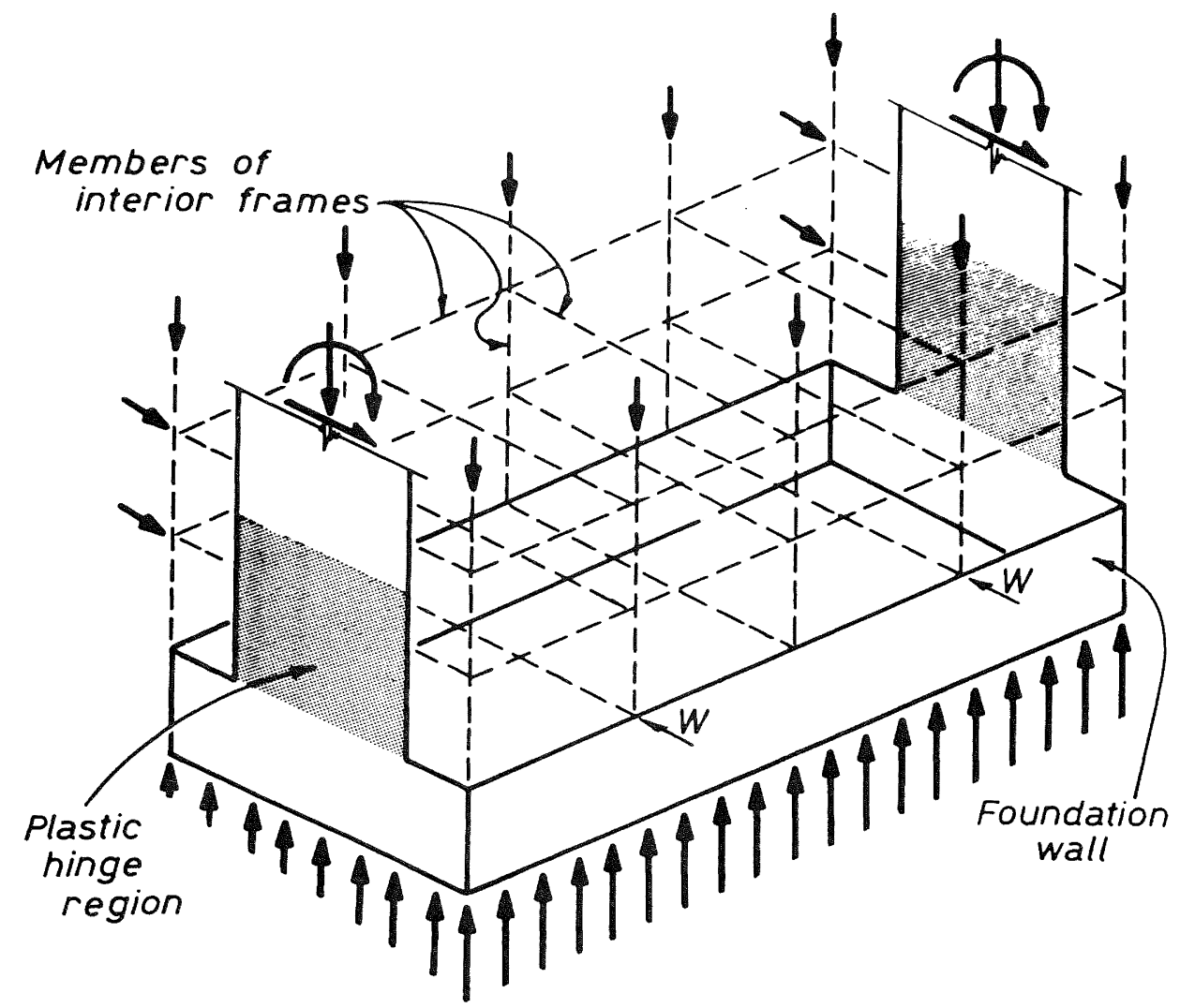

Fig. 5 - Foundations for cantilever walls situated at the boundaries 


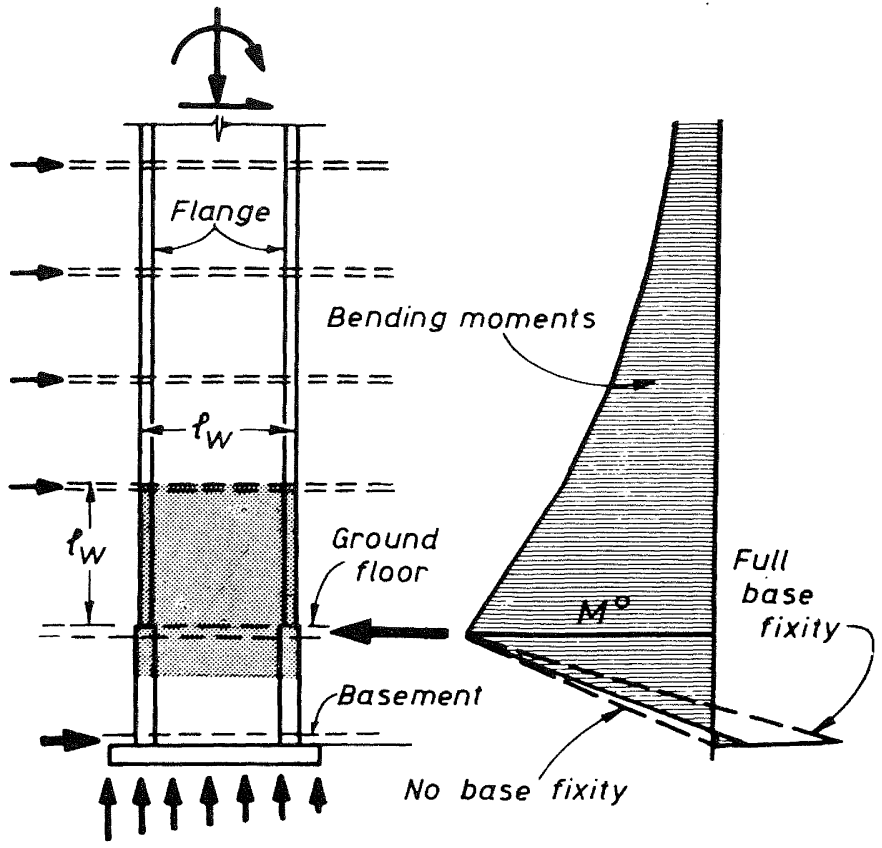

Fig. 6 - Base fixity for a cantilever wall through diaphragm action of floors.

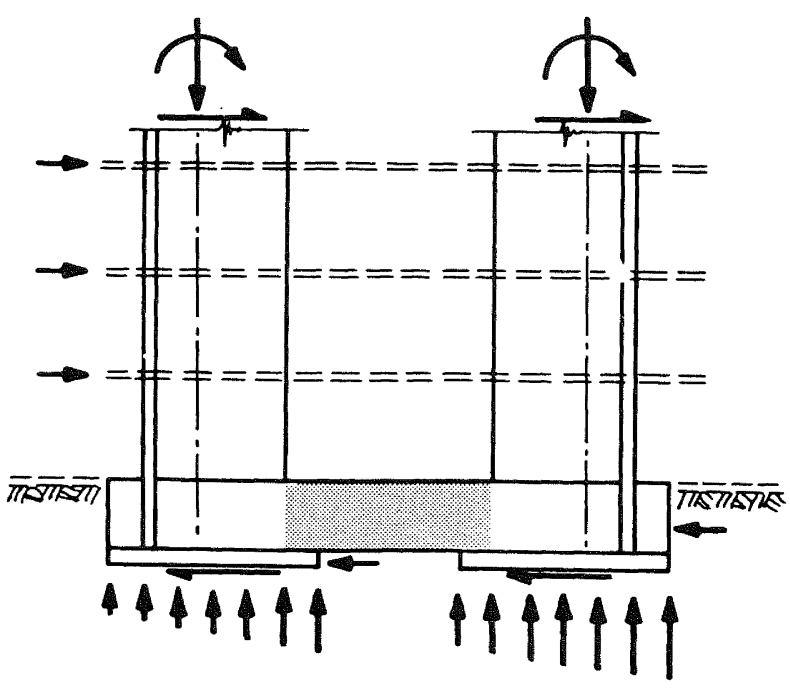

Fig. 7 - Ductile foundation for two cantilever walls 
the foundation to be the major source of energy dissipation. Accordingly, as figure 7 shows, the foundation wall-beam between two walls may be designed to develop the necessary plastic hinges. Such beams, should be treated the same way as coupling beams of shear walls and hence they should be reinforced with diagonal bars to resist fully both the moment and shear to be transferred between the two walls.

The moment of resistance to be assigned to the footings will depend on the relative stiffness of the soil. In most cases it will be expedient to design the foundation beams for full moment transfer and to assume that the footings transfer vertical concentric forces only.

Once the foundation beam is designed and its flexural overstrength is determined, it is possible to provide for the corresponding ideal strength at the base of the walls so that yielding in the walls should not need to be expected. This may then result in some saving in transverse reinforcement for shear, confinement and bar stability, because the shear walls would not need to be detailed for ductility.

Because of the nonsymmetric configuration of the wall sections, shown in figure 7, the flexural strength of one wall may be considerably less in one direction of the earthquake loading than in the other. If such is the case the designer may also choose to use a compromise whereby one wall and the foundation beam are made to yield, while the other wall cannot yeild when the direction of earthquake load-corresponds with its larger flexural strength.

\section{SUMMARY:}

It is recommended that the mechanisms of seismic load resistance and, when relevant, the modes of energy dissipation be clearly defined before a suitable foundation system is chosen for an earthquake resisting shear wall structure.

(b) The primary source of energy dissipation will generally be flexural yielding of the shear wall superstructure. Under special circumstances energy dissipation may be assigned to the foundation structure only.

(c) Appropriate capacity design procedures should ensure the proper strength relationship between the major inelastic, i.e. energy dissipating, and the elastic part of the entire structural system.

(d) Whichever part of the entire system (i.e. the shear wall superstructure or the foundation structure) is chosen to remain elastic, it should possess ideal strength equal to or in excess of the overstrength of the inelastic part of the system. (e) Components providing energy dissipation during the largest expected earthquake should be detailed to develop corresponding ductilities, while components assigned to remain elastic in any event should be exempted from the special seismic detailing requirements.

Shear walls together with their foundations should be allowed to rock, provided that this occurs at a lateral static design load which is in excess of that required for ductile shear wall structures $(S=1.0)$, and only if special studies, particularly with relevance to the ductility demands on non-rocking components of the structure, are carried out. Bearing areas of the foundations should be suitably proportioned to ensure that during rocking excessive inelastic deformations in the supporting soil, leading to premature misalignment of shear walls, will not occur.

\section{REFERENCES :}

1. Allardice, N.W., Fenwick, R.C., Taylor, P.W. and Williams, R.L., "Foundations for Ductile Frames" Section D, Seismic Design of Ductile Moment Resisting Reinforced Concrete Frames, Bulletin of the New Zealand Society for Earthquake Engineering, Vol. 11, No. 2, June 1978, pp. 122-128.

2. Taylor, P.W. and Williams, R.L., "Foundations for Capacity Designed Structures", Bulletin of the New Zealand National Society for Earthquake Engineering, Vol. 12, No. 3, June 1979, pp. 101-113.

3. Draft New Zealand Standard, DZ3101 "Code of Practice for the Design of Concrete Structures", Standards Association of New Zealand, Part 1 and 2, October 1978.

4. Taylor, R.G., "Introduction to and Aims in the Design of Earthquake Resisting Shear Wall Structures", Section 1, The Shear Wall Study Group of the New Zealand National Society for Earthquake Engineering, Bulletin of the New Zealand National Society for Earthquake Engineering, Vol. 13, No. 21980.

5. Paulay, T. and Williams, R.L. "The Analysis and Design of and the Evaluation of Design Actions for Reinforced Concrete Shear Wall Structures", Section B, The Shear Wall Study Group of the New Zealand National Society for Earthquake Engineering, Bulletin of the New Zealand National Society for Earthquake Engineering, Vol.13 No. 2, 1980.

6. Robinson, L.M., "Shear Walls of Limited Ductility", Section C, The 
Shear Wall Study Group of the New Zealand National Society for Earthquake Engineering, Bulletin of the New Zealand National Society for Earthquake Engineering, Vol. 13, No. 2,1980 .

7. NZS 4203: 1976, "Code of Practice for General Structural Design and Design Loadings for Buildings", Standards Association of New Zealand, $80 \mathrm{pp}$.

8. Priestley M.J.N., Evison, R.J. and Carr, A.J., "Seismic Response of Structures Free to Rock on their Foundations", Bulletin of the New Zealand National Society for Earthquake Engineering, Vol. 11, No. 3, September 1978, pp. 141-150.

9. Allardice, N.W.,"Parts and Portions", Section E, The Shear Wall study Group of the New Zealand National Society for Earthquake Engineering, Bulletin of the New Zealand National Society for Earthquake Engineering, Vol. 13, No. 3, 1980.

10. Park, R. and Paulay, T., "Reinforced Concrete Structures", John Wiley \& Sons, 1975, 769 pp. 